\title{
Note
}

\section{Jellyfish fishery in Pakistan}

\author{
Shahnawaz Gul ${ }^{1, *}$, Shahnaz JahangIR ${ }^{2}$ \& Agustín Schiariti ${ }^{3,4}$ \\ ${ }^{1}$ Department of Zoology, Jamia Millia Government Degree College, Shah Faisal Town, Karachi, Pakistan \\ ${ }^{2}$ Centre of Excellence in Marine Biology, University of Karachi, Karachi, Pakistan \\ ${ }^{3}$ Instituto Nacional de Investigación y Desarrollo Pesquero (INIDEP), Argentina \\ ${ }^{4}$ Instituto de Investigaciones Marinas y Costeras, CONICET, Universidad Nacional de Mar del Plata, (IIMyC), Argentina
}

Received 30 July 2015; Accepted 11 November 2015 Responsible Editor: Jun Nishikawa

\begin{abstract}
This study reports on the jellyfish (Cnidaria: Scyphozoa) fishery in Pakistan for the first time. Two jellyfish species: $\mathrm{Ca}$ tostylus perezi and Rhopilema hispidum, marketed with the trade names: banana and flower-jellyfish, respectively, are commercially exploited in Pakistan with the former being caught and exported in much higher relative quantities. C. perezi is fished in Balochistan, while $R$. hispidum is fished in Sindh province. Fishing seasons vary between February/March to July/August and 8-10 companies are regularly processing jellyfish, primarily using the oral arms, their fused-portion and scapulets, while umbrellas are typically not processed. The industry in the region has great potential because C. perezi occurs at high abundances in the northern Arabian Sea along the Balochistan coast of Pakistan.
\end{abstract}

Key words: Jellyfish, Scyphozoa, Catostylus perezi, Rhopilema hispidum, fishery, processing, Asia

Jellyfish (herein referring to medusae of the Class Scyphozoa, Order Rhizostomeae) are known as a delicacy of Chinese cooking (Hsieh \& Rudloe 1994, Li \& Hsieh 2004). Consumption of jellyfish is also popular in Asian countries other than China, including Japan, Malaysia, Korea, Taiwan, and other countries where there is strong market demand, generating a multi-million dollar business (Kingsford et al. 2000, Omori \& Nakano 2001, Hsieh et al. 2001, Nishikawa et al. 2008, Kitamura \& Omori 2010). In response to increasing demand for jellyfish commodities, other Asian countries have begun fishing jellyfish in recent decades, including Russia, Myanmar, Vietnam, India and Sri Lanka (Brotz 2015).

In Pakistan, the jellyfish fishery started in recent years exporting salted jellyfish to southeast Asian countries, mainly to Vietnam; the maximum amount exported in 2014 was approximately 1, 400 Metric Tons (Hamid B. Usmani, Marine Fisheries Department, Karachi, personal communication).

The Handbook of Fisheries Statistics of Pakistan, a compilation of data from 2004-2009 (Marine Fisheries Department 2012), provides the first published but brief description of the jellyfish fishery in Pakistan. Only one species of jellyfish, listed as Catostylus sp. with an annual catch of 2007-2009, is mentioned in the handbook (Table 1), and it lacks any information about the destination of the processed jellyfish products. So far, there is just one report (Muhammed \& Sultana 2008) that documents Rhizostoma pulmo (Macri, 1778) as an

*Corresponding author: Shahnawaz Gul; E-mail, gulshahnawaz@ yahoo.com edible jellyfish in Pakistan and points out that the previouslyreported Catostylus mosaicus (Quoy \& Gaimard, 1824) (see Tahera \& Kazmi 2006) is another commercially important jellyfish in Pakistan. However, recent studies (Gul \& Morandini 2013, 2015) have revealed that these records were based upon erroneous identifications. The available knowledge on the subject is, therefore, very poor and no further progress has so far been made in this regard. The present study is thus an attempt to unravel various aspects of the jellyfish fishery in the region for the first time.

We performed detailed field work during April 2015 (fishing season for Rhopilema hispidum) at Keti Bandar $\left(24^{\circ} 07^{\prime} 47^{\prime \prime} \mathrm{N}, 67^{\circ} 27^{\prime} 11^{\prime \prime} \mathrm{E}\right)$, Sindh province, and May to June 2015 (fishing season for Catostylus perezi) at Damb Bandar

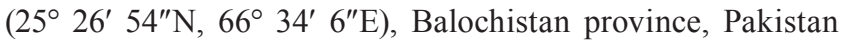
(Fig. 1). These are the two main areas where jellyfish harvested in the nearby offshore waters are landed and processed in jellyfish processing plants located along the shores. Various jellyfish processing plants at Keti- and Damb-Bandar were visited, and fishermen plus labourers, supervisors, and managers in the field were interviewed several times to collect

Table 1. Annual catch of Jellyfish (Catostylus sp.) in Pakistan.

\begin{tabular}{cc}
\hline Year & Total amount of catch in Metric Tons \\
\hline 2007 & 2,114 \\
2008 & 1,756 \\
2009 & 1,118 \\
\hline
\end{tabular}


information about the fishing methods and different steps involved in processing. Separation of the bell from the remaining parts of $C$. perezi was observed on boats in the landing area, but for $R$. hispidum this activity was carried out exclusively off shore and was thus studied using a video taken by the supervisor of a jellyfish processing plant. Processed products plus their packaging were also noted and photographed. We collected whole specimens of both the target species from the catch, examined them in the field, and also brought them back to the laboratory after preservation in 5\% formaldehyde solution in sea water. Specimens were identified following Kramp (1961), Omori \& Kitamura (2004), and Kitamura \& Omori (2010).

Two species of rhizostome jellyfish commercially exploited in Pakistan were recognized in the present study: Catostylus perezi Ranson, 1945 (Trade name: banana jellyfish) and Rhopilema hispidum (Vanhöffen, 1888) (Trade name: flower jellyfish).

Catostylus perezi (Family Catostylidae Claus, 1883) can be easily distinguished from its congeners in having a smooth exumbrella, but with numerous minute papillae on the exumbrellar surface of the velar lappets (Fig. 2a-b) (Kramp 1961, Gul \& Morandini 2013). Rhopilema hispidum (Family Rhizostomatidae Cuvier, 1800) is characterized by its roughsurfaced exumbrella with two kinds of warts - the minute, blunt, colourless, and the conical, pointed brown ones (Fig. $2 \mathrm{c}-\mathrm{d})$, and by the fact that each oral arm has many smaller club-shaped appendages on the sides and one larger terminal club-shaped appendage (Kramp 1961, Omori \& Kitamura 2004, Kitamura \& Omori 2010, Gul \& Morandini 2015). Both these scyphozoans were recently reported from Pakistani waters (Gul \& Morandini 2013, 2015).

Pakistani fishermen popularly call these jellyfish "Langara", meaning "aggregation of animals made of watery mass". The trade names are based upon the appearance of the remainder of the body after the bell has been cut away, herein termed the "oral appendages". This remainder is comprised of the oral arms, including their fused-portion, in both the target species, plus the scapulets in $R$. hispidum, which possesses them. These oral appendages look like a bunch of bananas and some kind of flower, respectively, hence the trade names "banana" and "flower" jellyfish.

Catostylus perezi is observed in high abundances in the waters offshore of Balochistan, where it is fished from Damb Bandar, Gadani, Hingol, Jiwani, Kalmat, Ormara and Pasni. In contrast, $R$. hispidum is more abundant in Sindh and is fished from Clifton, Ibrahim Haideri, Keti Bandar, Manora, Char creek, Chhan Waddo creek, Dabbo creek, Gharo creek, Kharo Chan creek, Kajar creek, Khuddi creek and Sir creek.

Commonly available fishing gear is used for catching the target jellyfish. $C$. perezi is fished using a gill net, while a kind of set-net, known locally as "Bhoola", is used for $R$. hispidum (Fig. 2e-h). Fishermen also carry hand nets to collect jellyfish from the surface waters. Fishing boats are of traditional design, made of wood and fitted with diesel engines.

Fishing seasons depend upon the climatic conditions, but

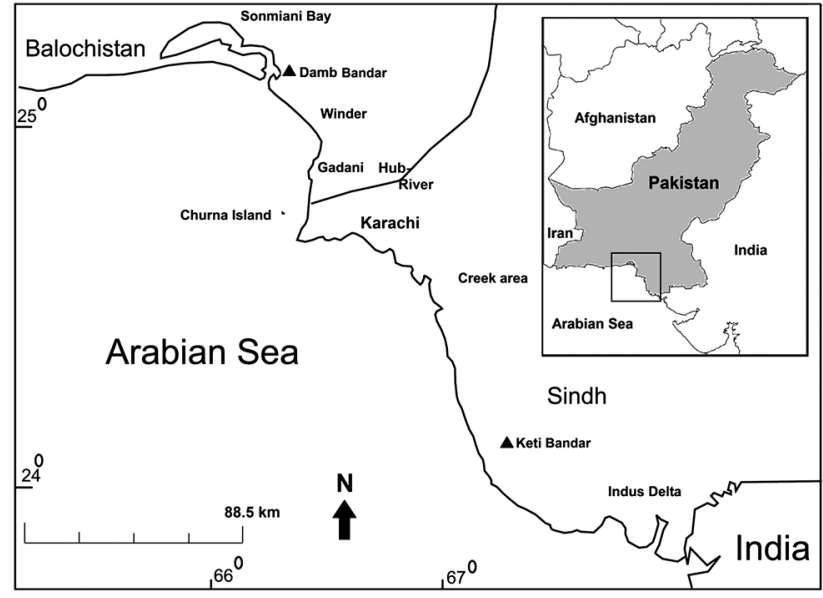

Fig. 1. Map showing study sites $(\boldsymbol{\Delta})$ : Damb Bandar (Balochistan) and Keti Bandar (Sindh) on the coast of Pakistan.

usually are between February/March to July/August; however, after the onset of the monsoon in June, the fishing activities become intermittent and are restricted to the creeks. In 2015, $R$. hispidum was fished and processed during March to April in Sindh and C. perezi from May to July in Balochistan.

Jellyfish processing plants are located on the shores where jellyfish are landed and are mostly temporary set-ups; at least 8-10 plants are regularly processing jellyfish in Pakistan. Fishermen remove the umbrellas at sea and discard them, keeping only the oral appendages, which are then sold to the processing plants. In the case of $R$. hispidum these are then further separated into scapulets, oral arms, and the fusedportion of the oral arms. The various parts of the oral appendages are then processed separately (in R. hispidum) or whole/ together (in $C$. perezi). The material soaked in salt solution, having been previously washed and treated with a mixture of salt and alum, is then packed into plastic buckets (Fig. 2i-v). In 2015, fishermen sold oral appendages of $C$. perezi at about 40-50 PKR (0.38-0.48\$) per kg, while those of $R$. hispidum fetched 30 PKR (0.28\$) per piece, with each piece ranging from 0.5 to $6 \mathrm{~kg}$.

In Pakistan, labourers in seafood processing companies usually work on daily wages. When the jellyfish season is over, they return to normal fishing and processing of other seafoods, using the same nets and boats, but the end of fishing activity is definitely a time of financial instability for them.

The jellyfish industry in Pakistan has great potential as $C$. perezi is in high demand. This is because the species is abundant in the northern Arabian Sea along the coast of Balochistan during the warmer months. We recommend that Pakistani companies process the whole specimen of the target species, including the bell. This would be economically beneficial for local fishermen, as the present practice of not processing the bells reduces the fishermen's profit by nearly $50 \%$. Conversely, in other countries (China, Japan, Vietnam, etc.), the bells of $R$. hispidum are processed and in some cases fetch a higher price than the oral arms (see Kingsford et al. 2000, Omori \& Nakano 2001, Hsieh et al. 2001, Nishikawa et 

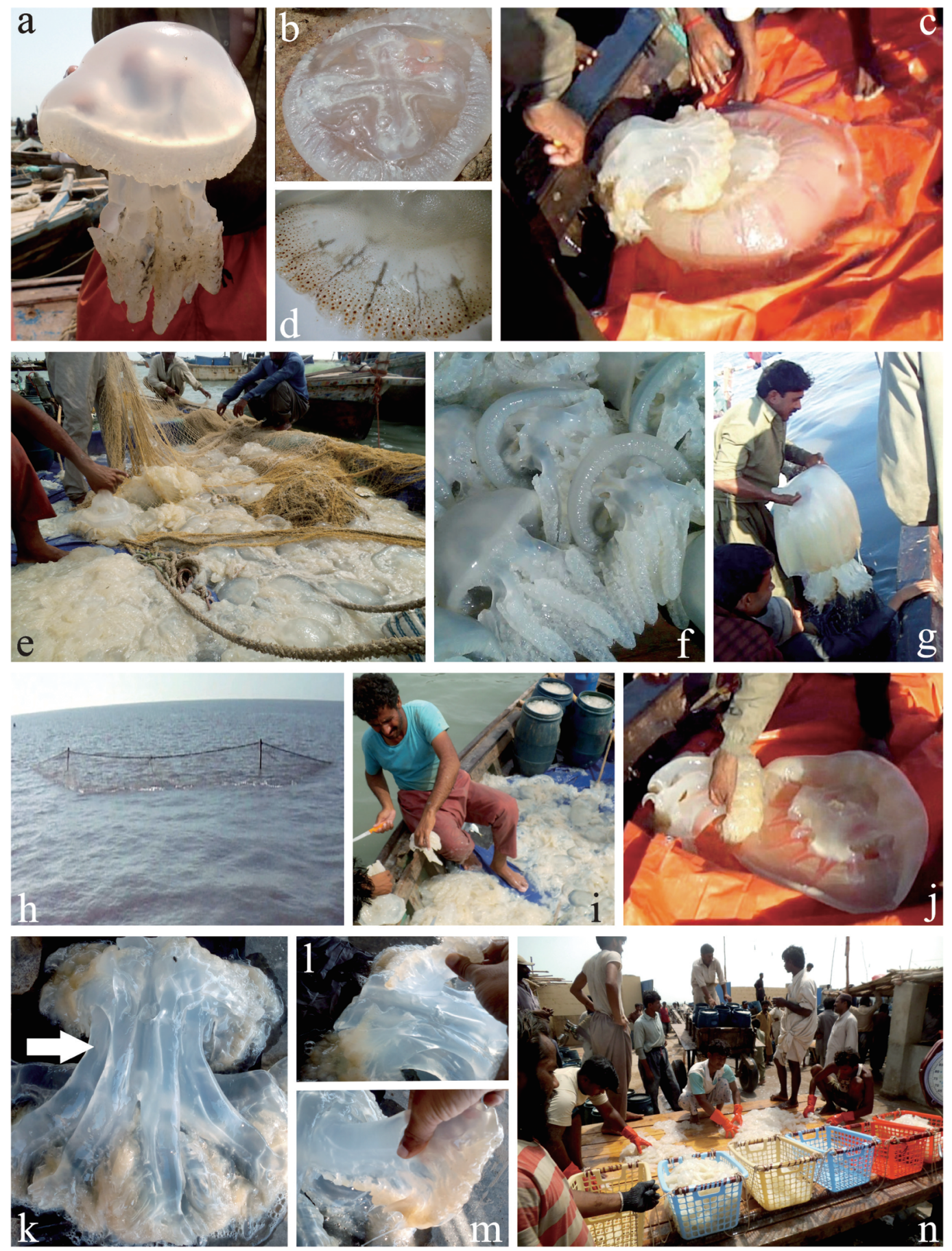

Fig. 2. (a-b) Catostylus perezi Ranson, 1945: (a) specimen from the catch, (b) discarded bell. (c-d) Rhopilema hispidum (Vanhöffen, 1888): (c) specimen from the catch, (d) close up of bell. (e-h) Jellyfish catch: (e) C. perezi in a gillnet, (f) close up of $C$. perezi catch, (g) fisherman picking $R$. hispidum from the net, (h) a kind of set-net locally called "Bhoola" fixed in water for catching $R$. hispidum. (i-j) Separation of oral appendages of: (i) C. perezi, (j) R. hispidum. (k-m) Oral appendages of $R$. hispidum: (k) arrow points to the fused-portion, (1) showing scapulets and, (m) oral arms. (n) Oral appendages of jellyfish in small barrels are transported to the processing plants where they are sold.

\section{al. 2008).}

Increasing jellyfish blooms in coastal environments could be a problem for some industries (e.g. Purcell 2012), but fishing jellyfish for food and also for extracting biological compounds may help to control population sizes and reduce their detrimental effects. The consequences of both blooming of jellyfish and also the removal of large numbers of jellyfish remain unclear, as scientific studies are not keeping pace. If jellyfish population dynamics are not well understood, overfishing of jellyfish stocks may also occur. In fact, overfishing is likely one of the main reasons for the decline of Rhopilema esculentum Kishinouye, 1891 catches in Chinese waters 

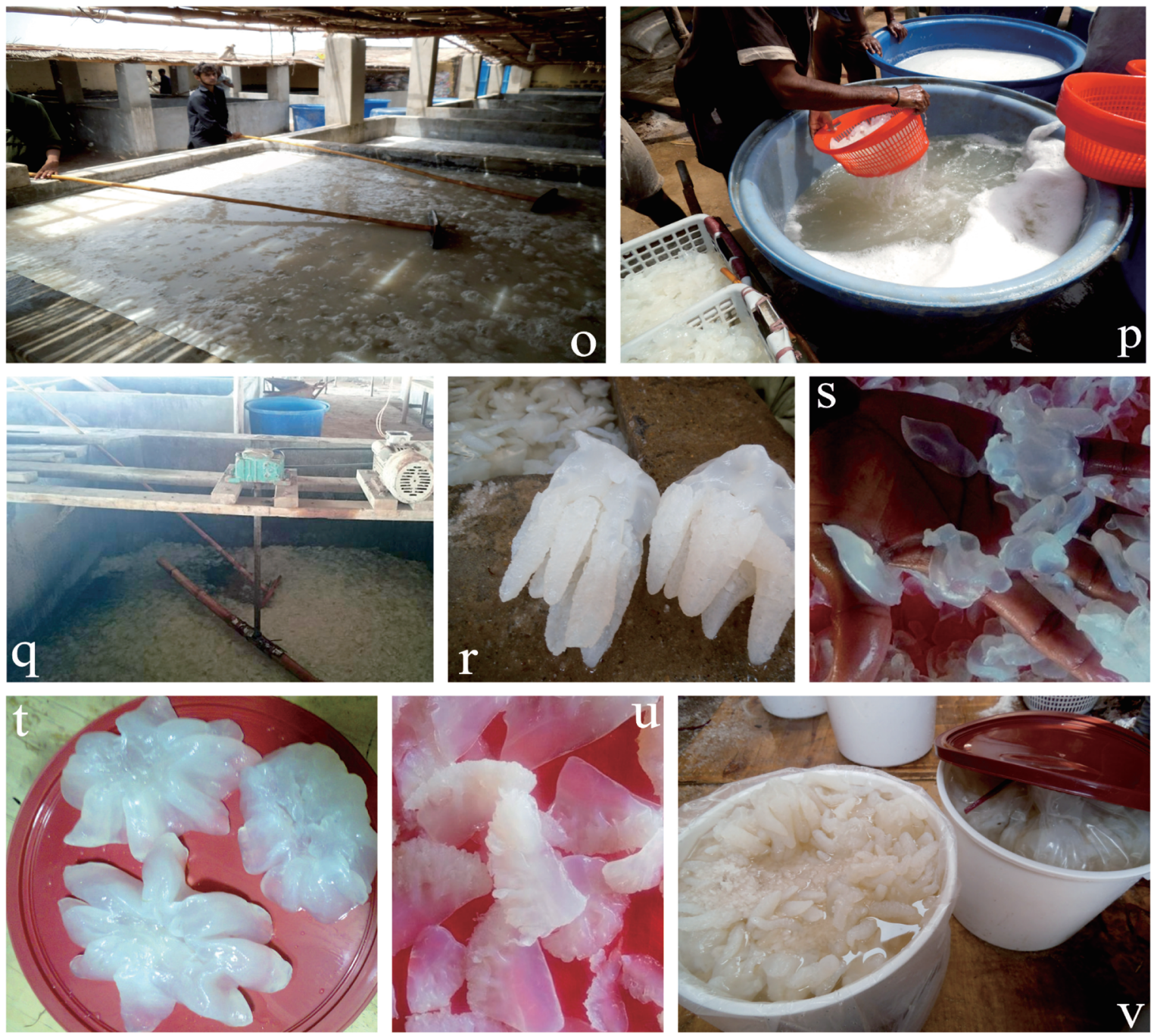

Fig. 2. (o-q) Washing: (o) wooden stirrers are used for washing of oral appendages of $C$. perezi in ponds and, (p) large plastic tubs are also used when all ponds are full, (q) electric motor with wooden stirrer is fixed over the pond for washing in the case of R. hispidum. (r-u) Ready-product: (r) oral appendages of $C$. perezi, (s) scapulets, (t) fused-portions of oral arms and, (u) oral arms of $R$. hispidum. (v) Packing of $C$. perezi ready-product in plastic buckets (bucket lid $28 \mathrm{~cm}$ diameter).

\section{(Dong et al. 2014).}

It is imperative to start recording and registering data about the distribution patterns and abundances of edible species, along with more comprehensive studies of potential areas for exploitation. The improvement of salting/processing techniques and marketing of jellyfish bells would benefit the development of the industry in Pakistan. Gathering and analyzing information will lead to better management practices and conservation policies. Describing basic aspects of the life history and population dynamics of the target species in Pakistan (e.g. life cycles, sexual and asexual reproductive strategies, trophic relationships, etc.) should also be a priority.

\section{Acknowledgements}

We would like to thank the anonymous reviewers for comments and corrections to the manuscript. We acknowledge Habibullah Khan, Nasir U. Rahimoo \& Sohail Soomro (Dua
SeaFood) for providing help in collecting information on catching and processing of jellyfish in Pakistan, and to Hamid B. Usmani (Marine Fisheries Department, Karachi) for updates on the export of Pakistani salted jellyfish. The contribution of AS is partially founded by CONICET PIP 2013-00615 and PICT 2013-1773. This is INIDEP contribution No. 1953.

\section{References}

Brotz L (2015) Jellyfish fisheries—a global assessment. In: Pauly D and Zeller D (eds) Global Atlas of Marine Fisheries: Ecosystem Impacts and Analysis. Island Press, Washington, DC, USA, 77-81.

Dong Z, Liu D, Keesing JK (2014) Contrasting trends in populations of Rhopilema esculentum and Aurelia aurita in Chinese waters. In: Pitt KA and Lucas CH (eds) Jellyfish Blooms. Springer, London, 207-218. Gul S, Morandini AC (2013) New records of scyphomedusae from Pakistan coast: Catostylus perezi and Pelagia cf. noctiluca (Cnidaria: Scyphozoa). Mar Biodivers Rec 6 (e86): 1-6.

Gul S, Morandini AC (2015) First record of the jellyfish Rhopilema his- 
pidum (Cnidaria: Scyphozoa) from the coast of Pakistan. Mar Biodivers Rec 8 (e30): 1-4.

Hsieh YHP, Rudloe J (1994) Potential of utilizing jellyfish as food in Western countries. Trends Food Sci Tech 5: 225-229.

Hsieh YHP, Leong FM, Rudloe J (2001) Jellyfish as food. Hydrobiologia 451: 11-17.

Kingsford MJ, Pitt KA, Gillanders BM (2000) Management of jellyfish fisheries, with special reference to the Order Rhizostomeae. Oceanogr Mar Biol 38: 85-156.

Kitamura M, Omori M (2010) Synopsis of edible jellyfishes collected from Southeast Asia, with notes on jellyfish fisheries. Plankton Benthos Res 5(3): 106-118.

Kramp PL (1961) Synopsis of the medusae of the world. J Mar Biol Ass UK 40: 7-469.

Li J, Hsieh YHP (2004) Traditional Chinese food technology and cuisine. Asia Pac J Clin Nutr 13(2): 147-155.

Marine Fisheries Department (2012) Handbook of fisheries statistics of Pakistan. Vol. 20. Marine Fisheries Department, Government of Paki- stan, Fish Harbour, West Wharf, Karachi. 217 pp.

Muhammed F, Sultana R (2008) New record of edible jellyfish, Rhizostoma pulmo (Cnidaria: Scyphozoa: Rhizostomitidae) from Pakistani waters. Mar Biodivers Rec 1(e67): 1-3.

Nishikawa J, Thu NT, Ha TM, Thu PT (2008) Jellyfish fisheries in northern Vietnam. Plankton Benthos Res 3(4): 227-234.

Omori M, Nakano E (2001) Jellyfish fishery in Southeast Asia. Hydrobiologia 451: 19-26.

Omori M, Kitamura M (2004) Taxonomic review of three Japanese species of edible jellyfish (Scyphozoa: Rhizostomeae). Plankton Biol Ecol 51: $36-51$.

Purcell, JE (2012) Jellyfish and ctenophore blooms coincide with human proliferations and environmental perturbations. Annu Rev Mar Sci 4: $1-27$.

Tahera Q, Kazmi QB (2006) New records of two jellyfish medusae (Cnidaria: Scyphozoa: Catostylidae: Cubozoa: Chirodropidae) from Pakistani waters. Mar Biodivers Rec 1 (e30): 1-4. 